\title{
15-Hydroxyprostaglandin dehydrogenase in the bovine endometrium during the oestrous cycle and early pregnancy
}

\author{
Marianne Parent, Eric Madore, Leslie A MacLaren and Michel A Fortier \\ Unité de Recherche en Ontogénie et Reproduction Centre Hospitalier Universitaire de Québec and Département \\ d'Obstétrique et Gynécologie, and Centre de Recherche en Biologie de la Reproduction, Université Laval, \\ Sainte-Foy, Québec G1V 1K3, Canada
}

Correspondence should be addressed to M A Fortier; Email: MAFortier@crchul.ulaval.ca

\begin{abstract}
Prostaglandins (PG) are primary regulators of reproductive function. In ruminants, the relative production of $\mathrm{PGE}_{2}$ and $\mathrm{PGF}_{2 \alpha}$ determines the return to a new oestrous cycle or to the establishment of pregnancy in response to a viable embryo. PG action depends on biosynthesis, transport and interaction with their receptors, which are all expressed differentially during the oestrous cycle. PGs are, however, local mediators and thus the onsite degradation by enzymes such as 15-hydroxyprostaglandin dehydrogenase (HPGD), also known as 15-PGDH, is another factor to consider in the regulation of physiological action. Little information is available on PG catabolism in the endometrium during the oestrous cycle or early pregnancy. The purpose of this study was to clone the bovine 15-PGDH, produce the recombinant protein and generate a specific antibody to study its activity and its expression in the endometrium during the oestrous cycle. We have found that the bovine 15-PGDH is highly homologous to the rat and human isoforms. 15-PGDH is localized principally in the glandular epithelium and to a lesser extent in stromal and luminal epithelial cells. The enzyme expression is regulated during the oestrous cycle and it reaches its maximal level on days 16-18. Transient expression is observed in luminal epithelial and trophoblast cells on day 21 of pregnancy. The mRNA is expressed at a constant high level throughout the cycle. The activity of the recombinant 15-PGDH was also tested and was found comparable for $\mathrm{PGF}_{2 \alpha}$ and $\mathrm{PGE}_{2}$. These data suggest that 15-PGDH contributes to the tight regulation of PG action in the endometrium especially at the critical period of recognition of pregnancy.

Reproduction (2006) 131 573-582
\end{abstract}

\section{Introduction}

Prostaglandins (PGs) are potent mediators for a wide variety of physiological and pathological processes and are produced in all nucleated cells. These molecules are recognized as local mediators acting primarily in the tissue where they are produced. PGs are particularly important in the regulation of female reproductive function where they control ovulation, menses, establishment and maintenance of pregnancy and parturition (Arosh et al. 2004a, 2004b, Kang et al. 2005). The regulation of the prostaglandin system is complex and can occur at the biosynthesis, catabolism, transport and receptor levels. Catabolism of PGs occurs primarily in vascular beds such as the lung, kidney and placenta, but expression of 15-hydroxyprostaglandin dehydrogenase (HPGD), also known as $15-\mathrm{PGDH}$, in peripheral tissues suggests that local catabolism can also contribute to peripheral regulation of PG action.
Prostaglandins exhibit a very short half-life in vivo due to chemical instability and local or pulmonary inactivation by the catabolic enzymes PGDHs (Pace-Asciak 1980). As mentioned above, the lung is the primary catabolic site for PGs and just one passage in the pulmonary circulation is sufficient to almost completely metabolize $\mathrm{PGE}_{1}, \mathrm{PGE}_{2}$ and $\mathrm{PGF}_{2 \alpha}$ in cats, dogs, rats and guinea-pigs (Piper et al. 1970 ), and to metabolize from $65 \%$ to $99 \%$ in ruminants (McCracken et al. 1999). The first step for biological inactivation of PGs (Fig. 1) is the oxidation of the 15-hydroxyl group to a 15-keto group by 15-PGDH (Kankofer 1999, Patel \& Challis 2001). The enzyme is able to catalyse reversible oxido-reduction of prostaglandins at C15 depending on $\mathrm{pH}$, with oxidation at $\mathrm{pH} 9.0$ and reduction at pH 5.5 (Yamasaki \& Sasaki 1975). Further catabolism occurs when the double bond at the C13-14 position is removed by the 15-ketoprostaglandin 13-reductase (15-13PGR), resulting in 13,14-dihydro-15-keto-prostaglandins, the so called PG(A, D, F, E)M (Kankofer 1999). The 13,14-dihydro-15-keto-prostaglandins finally undergo 


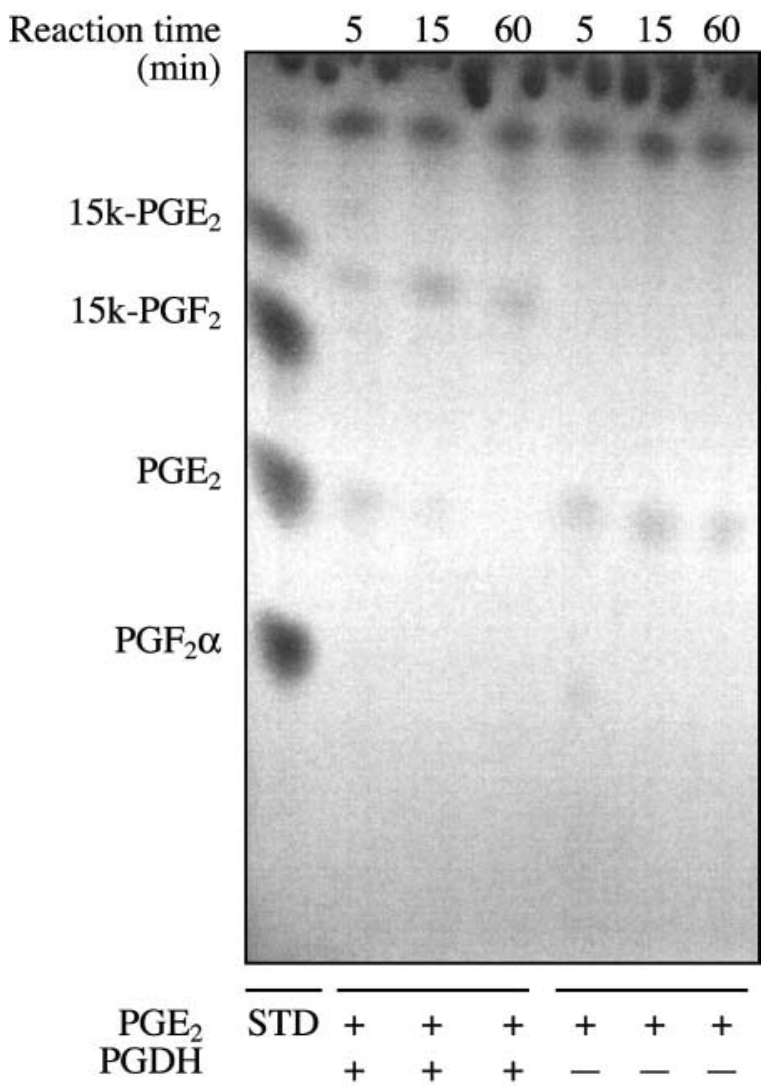

Figure 1 Catabolism of $\mathrm{PGE}_{2}$ by rbPGDH. $\mathrm{PGE}_{2}(500 \mu \mathrm{M})$ in $0.1 \mathrm{M}$ Tris- $\mathrm{HCl}\left(\mathrm{pH}\right.$ 9.0) containing $1 \mathrm{mM} \mathrm{NAD}^{+}$was incubated in the presence or not of $4 \mu \mathrm{g}$ recombinant $15-\mathrm{PGDH}$ at $25^{\circ} \mathrm{C}$ for 5,15 or $60 \mathrm{~min}$. Prostaglandins were extracted, resuspended in chloroform: methanol (2:1) and loaded on TLC plates as described in Materials and Methods. After migration, PG spots were revealed with phosphomolibdic acid, $10 \%$ in methanol. The first column on the left represents PG and 15K PG standards (STD), the next 3 columns represent $\mathrm{PGE}_{2}$ in the presence of $15-\mathrm{PGDH}$ for 5,15 and $60 \mathrm{~min}$ and the last 3 columns represent $\mathrm{PGE}_{2}$ without $15 \mathrm{PGDH}$ at the same times. One representative TLC out of 3 made is shown.

$\beta$ - and $\omega$-oxidation to form a variety of metabolites that are excreted in the urine (Okita \& Okita 1996).

There are two types of 15-PGDH, the first being a homodimeric protein known as $\mathrm{NAD}^{+}$-dependent $\mathrm{PGDH}$, initially identified in the lung (Piper et al. 1970). The other is a cytosolic monomeric enzyme identified as NADP ${ }^{+}$ dependant PGDH, found in human liver (Lin \& Jarabak 1978). The primary substrates for the type $1 \mathrm{PGDH}$ $\left(\mathrm{NAD}^{+}\right.$-dependant) are prostaglandins and related eicosanoids (Jarabak \& Fried 1979) whereas type II PGDH (NAPD $^{+}$-dependant) possesses a much broader substrate specificity (Lin \& Jarabak 1978). The type II enzyme has a much higher $K_{\mathrm{m}}$ value for PGs than type I, thus it does not appear to contribute significantly to the catabolism of prostaglandins (Ensor \& Tai 1995, Tai et al. 2002). For this reason, only type I PGDH was considered in the present study.
15-PGDH is present in most mammalian tissues and has been purified and cloned in different mammals, such as human, rat, mouse and water buffalo (Bubalus sp) (Ensor et al. 1990, Matsuo et al. 1996, Zhang et al. 1997, Mak \& Lee 1998). In situ catabolism of prostaglandins allows a rapid and direct regulation of local mechanisms mediated by these hormones. There is some evidence that expression of 15-PGDH in the uterus is regulated by sex steroids (Matsuo et al. 1997, Greenland et al. 2000). The promoter sequence of the mouse 15-PGDH gene contains both oestrogen and glucocorticoid response elements as well as AP-1 and AP-2 sites (Matsuo et al. 1997). The human 15-PGDH promoter appears to be under the control of Ets, AP-1, cAMP and prolactin (PR) (Greenland et al. 2000). On the other hand, it has been demonstrated that 15-PGDH activity is low in bovine placenta, endometrium and fetal membranes during late gestation and parturition (Janszen et al. 1994) by comparison with the high levels found in humans and sheep.

There is currently a lot of information available on the expression and the regulation of 15-PGDH during pregnancy and labour for different species (Ensor et al. 1990, Janszen et al. 1994). The human PGDH gene is regulated by progesterone and, during pregnancy, progesterone and cortisol have been proposed as positive and negative regulators of PGDH expression respectively (Greenland et al. 2000, Patel \& Challis 2002). However, very little is known about the expression and action of PGDH in the endometrium during the oestrous cycle. Timely action of PGs of endometrial origin is critical for recognition of pregnancy or for return to a new cycle in ruminants. Therefore, we hypothesize that PGDH is present in the bovine endometrium and its protein is regulated during the oestrous cycle to exert a fine control of net PG output in this tissue.

\section{Materials and Methods}

\section{Materials}

The TOPO TA-Cloning pCR2.1 cloning kit, the One Shot kit and restriction enzymes and buffers were purchased from Invitrogen (Carlsbad, CA, USA). Oligonucleotides were synthesized with DNA Synthesizer ABI-394 from Applied Biosystem Inc. (Foster City, CA, USA). Recombinant taq and Ready-to-Go cDNA labelling kit were obtained from Amersham Pharmacia Biotech (Baie d'Urfé, Qc, Canada). The T7 DNA polymerase sequencing kit was purchased from USB Corporation (Cleveland, $\mathrm{OH}$, USA). The $\left[\alpha-{ }^{35} \mathrm{~S}\right] \mathrm{dATP},\left[\alpha-{ }^{32} \mathrm{P}\right] \mathrm{dCTP},\left[\gamma^{3}{ }^{32} \mathrm{P}\right]$ ATP and Renaissance Western blot chemiluminescence reagent were all obtained from PerkinElmer Life Science (Markham, On, Canada). The pET-16b plasmid and His-Bind kit were from Novagen (Madison, WI, USA). The NAD ${ }^{+}, \mathrm{PGE}_{2}, \mathrm{PGF}_{2 \alpha}$, TRIzol reagent, Harris haematoxylin, ampicillin and chloramphenicol were purchased from Sigma Chemical Co. (St Louis, MO, USA). The nitrocellulose membrane was purchased from Bio-Rad Laboratories (Hercules, CA, USA) 
and the BrightStar Plus membrane and ULTRAhyb solution were obtained from Ambion Inc. (Austin, TX, USA). The goat anti-rabbit antibody was obtained from Dako Diagnostics Canada Inc. (Missisauga, On, Canada). The Vectastain Elite $\mathrm{ABC}$ kit was purchased from Vector Laboratories Inc. (Burlingame, CA, USA). BioMax films were from Eastman Kodak Corporation (New York, NY, USA).

\section{Sequencing of bovine pulmonary PGDH}

PGDH was amplified by PCR (30 cycles, annealing at $60^{\circ} \mathrm{C}$ ) using cDNA from bovine (Bos taurus) lung collected at the slaughterhouse. The sequences for the primers were derived from the 15-PGDH of Bubalus sp (water buffalo). The sequence for the forward primer was 5'-ATGCACGTGAACGGCAAAGTGG-3' and for the reverse primer the sequence was $5^{\prime}$-TCACTGCATTTTCATGTGAAATGG-3'. The PCR product was introduced into the pCR2.1-TOPO vector following the manufacturer's instructions, and $\mathrm{PGDH}$ sequencing was carried out manually with a T7 DNA polymerase sequencing kit.

\section{Construction of the expression plasmid and purification of PGDH His-tag}

Nde1 restriction endonuclease sites were inserted at each end of the 15-PGDH coding sequence during amplification by PCR. This fragment was ligated into $\mathrm{pET}-16 \mathrm{~b}$ vector to add a His-tag sequence in the $\mathrm{N}$-terminal of $\mathrm{PGDH}$. The ligation reaction was used to transform BL21CD ${ }^{+}$bacteria, and transformants expressing PGDH protein were isolated. These transformants were grown until the $\mathrm{OD}_{600}$ reached 0.4 in Luria Broth (LB) medium containing $0.2 \mathrm{mg} / \mathrm{ml}$ ampicillin and $40 \mu \mathrm{g} / \mathrm{ml}$ chloramphenicol. The production of 15 -PGDH protein was induced by $1 \mathrm{mM}$ isopropylthio- $\beta$ galactosyl (IPTG) for $4 \mathrm{~h}$ at $37^{\circ} \mathrm{C}$. The recombinant PGDH His-tag protein overexpressed in Escherichia coli was purified on a nickel-nitrilotriacetic acid column (Ni-NTA Hisbind resin) according to the manufacturer's protocol. The only difference was the use of glycine- $\mathrm{NaOH} 12.5 \mathrm{mM}$ solution ( $\mathrm{pH}$ 9.0) containing $100 \mathrm{mM}$ imidazole as the eluant to prevent precipitation of 15-PGDH protein. The protein was kept in the same solution (without imidazole) containing $10 \%$ glycerol.

\section{Assay of bovine recombinant PGDH activity}

The activity of recombinant bovine (rb) 15-PGDH protein was estimated at $25^{\circ} \mathrm{C}$ by spectrophotometric measurement of the formation of $\mathrm{NADH}$ at $340 \mathrm{~nm}$ as described by Braithwaite \& Jarabak (1974) and Ensor \& Tai (1992). Briefly, the reaction was started by adding $1 \mu \mathrm{g}$ rb-PGDH to $1 \mathrm{ml}$ of a mixture containing 15 to $100 \mu \mathrm{M} \mathrm{PGE}$ or $\mathrm{PGF}_{2 \alpha}, 0.1 \mathrm{M}$ Tris- $\mathrm{HCl}(\mathrm{pH} 9.0)$ and $0.45 \mathrm{mM} \mathrm{NAD}{ }^{+}$. One unit of enzyme is defined as the formation of $1 \mu \mathrm{mol}$ $\mathrm{NADH}$ per min. The formation of 15 -keto-PGE 2 and 15-keto-PGF $2_{\alpha}$ was also verified (Fig. 1). For that experiment, $500 \mu \mathrm{l}$ reaction mixture containing $500 \mu \mathrm{M} \mathrm{PGE}_{2}$ or
$\mathrm{PGF}_{2 \alpha}, 0.1 \mathrm{M}$ Tris-HCl (pH 9.0), $1 \mathrm{mM} \mathrm{NAD}{ }^{+}$and $4 \mu \mathrm{g}$ recombinant $15-\mathrm{PGDH}$ were incubated at $25^{\circ} \mathrm{C}$ for 5,15 or $60 \mathrm{~min}$. The reaction was stopped with an equal volume of $0.2 \mathrm{M} \mathrm{HCl}$. Prostaglandins were then extracted with $300 \mu \mathrm{l}$ ethyl acetate per $100 \mu \mathrm{l}$ reaction mixture and the organic solvent was evaporated under a nitrogen stream. Samples were resuspended in chloroform:methanol $(2: 1)$ and loaded on TLC plates. The migration carrier was ethyl acetate:2, 2, 4-trimethylpentane:acetic acid (110: 50:20) saturated with water. Finally, PG spots were revealed with phosphomolibdic acid, $10 \%$ in methanol.

\section{Preparation of PGDH antiserum}

Three female New Zealand White rabbits weighing $2.5 \mathrm{~kg}$ were bled on day -1 to generate pre-immune serum. On day 0 , each rabbit received subcutaneous injections of the antigen mixture composed of $500 \mu \mathrm{g}$ rbPGDH in $1 \mathrm{ml}$ $0.2 \mathrm{M}$ glycine- $\mathrm{NaOH}$, pH 9.5, mixed with $1 \mathrm{ml}$ Freund's Complete Adjuvant at 4 different sites (250 $\mu$ l per site). A first boost was carried out 6 weeks later at half the concentration of antigen and this process was repeated twice at 3-week intervals. Bleeding was performed following each immunization to evaluate the titre by Western blotting using purified rbPGDH as the antigen. After the fourth boost, animals were killed, blood was collected and the antiserum was prepared. One of the rabbits yielded our working antiserum for both Western blot and immunohistochemistry at a dilution of $1 / 2000$.

\section{RNA isolation and protein extraction}

Bovine uteri were collected at the slaughterhouse, and the day of the oestrous cycle was determined based on ovarian and uterine tissue characteristics and a cycle length of 21 days (Arosh et al. 2002). Twenty-one animals covering the entire oestrous cycle were used to generate corresponding mRNA and protein samples. The samples were divided into 7 groups of 3 animals representing days $1-3$, $4-6,7-8,10-12,13-15,16-18$ and 19-21. Endometrial tissues were processed as described previously (Arosh et al. 2002). Briefly, mixed endometrial cells were scraped with a scalpel blade, washed by centrifugation at $2000 \mathrm{~g}$ in PBS to eliminate contaminating fat and blood, and $1 \mathrm{~g}$ wet weight each was used for RNA and protein extraction. For RNA, the cell pellet was put in TRIzol reagent and extraction was conducted according to the manufacturer's instructions. Protein extraction and quantification were carried out as described previously (Chapdelaine et al. 2001). The cell pellet was put in lysis buffer $(10 \mathrm{mM}$ Tris- $\mathrm{HCl}$, pH 7.4, 1\% SDS, 1 mM PMSF, $1 \mathrm{mM}$ dithiothreitol (DTT)) and homogenized for $30 \mathrm{~s}$ on ice with a Polytron homogenizer (Brinkman Instruments). Bovine lung was diced, put in homogenization buffer (20 mM Tris- $\mathrm{HCl}, \mathrm{pH} 7.4,1 \mathrm{mM}$ EDTA, 10\% glycerol, $1 \mathrm{mM}$ PMSF, $1 \mathrm{mM}$ DTT) and homogenized 3 times for $30 \mathrm{~s}$ each on ice with the Polytron. Total proteins from the 
supernatants were obtained by methanol/chloroform extraction. Protein samples were resuspended in SDS-PAGE loading buffer $(100 \mathrm{mM}$ Tris-HCl, $\mathrm{pH} 7.4$, $200 \mathrm{mM}$ DTT, 4\% bromophenol blue, 20\% glycerol) and boiled for $3 \mathrm{~min}$. Protein concentration was estimated using $1 \mu$ l of the sample.

\section{Northern blot analysis}

Total RNA $(20 \mu \mathrm{g})$ was loaded on a $1.2 \%$ formaldehyde agarose gel, electrophoresed and transferred onto a nylon membrane. The membrane was prehybridized for $3 \mathrm{~h}$ in ULTRAhyb solution at $45^{\circ} \mathrm{C}$. The probe was full length double stranded PGDH cDNA, which was labelled with $\left[\alpha-{ }^{32} \mathrm{P}\right] \mathrm{dCTP}$ according to the standard protocol of the Ready-to-Go cDNA labelling kit. The probe was then added to the ULTRAhyb solution and hybridized overnight at $45^{\circ} \mathrm{C}$. The membranes were washed 3 times at $68^{\circ} \mathrm{C}$ in saline sodium citrate (SSC) $2 \times$ then 2 times in $0.2 \times$, for $15 \mathrm{~min}$ each. Membranes were exposed for 4-5 days, at $-80^{\circ} \mathrm{C}$ on X-omat films (Kodak) before developing. Bands were quantified by Alpha-Imager 2000 software (Alpha Innotech Corp., San Leandro, CA, USA). The membrane was then boiled in water and used for a second hybridization with the $18 \mathrm{~S}$ probe. The membrane was prehybridized for about $1 \mathrm{~h}$ at $56^{\circ} \mathrm{C}$ in a solution containing $6 \times$ STE buffer $(0.9 \mathrm{M} \mathrm{NaCl}, 0.18 \mathrm{M}$ Tris- $\mathrm{HCl}, 6 \mathrm{mM}$ EDTA, $\mathrm{pH}$ 8.0), $1 \times$ Denhardt's reagent, $10 \mathrm{ng} / \mathrm{ml}$ salmon sperm DNA and $0.2 \%$ SDS. The oligonucleotide probe was labelled with $\left[\gamma_{-}{ }^{32} \mathrm{P}\right]$ ATP using T4 kinase. The probe was then added to the prehybridization solution and hybridized overnight at $56^{\circ} \mathrm{C}$. Membranes were washed 3 times with $2 \times \mathrm{SSC}$ at $68^{\circ} \mathrm{C}$ then exposed as previously described.

\section{Western blot analysis}

Fifteen micrograms total protein were loaded on a $10 \%$ SDS-polyacrylamide gel and transferred onto a nitrocellulose membrane. The membrane was incubated in 5\% fat-free dry milk powder in PBS and 0.05\% Tween-20 (PBS-T), overnight at $4{ }^{\circ} \mathrm{C}$. Membranes were then incubated for $1 \mathrm{~h}$ at room temperature in $2.5 \%$ fat-free dry milk powder in PBS-T containing a 1:500 dilution of rabbit anti-bovine $\mathrm{PGDH}$ (rabbit immunizations were performed using $4 \times 250 \mu \mathrm{g}$ purified recombinant bovine PGDH protein) or with anti- $\beta$-actin (1:5000). Membranes were washed for $30 \mathrm{~min}$ in PBS-T. The second antibody, either goat anti-rabbit antibody conjugated to horseradish peroxidase for $\mathrm{PGDH}$ or goat anti-mouse antibody for $\beta$-actin (dilution 1:10000 in 2.5\% fat-free dry milk powder in PBS-T) were incubated with membranes for $45 \mathrm{~min}$ at room temperature. Membranes were washed for $45 \mathrm{~min}$ in PBS-T. Bands were revealed by addition of a chemilumunescent substrate (ECL) according to the manufacturer's instructions. The blots were then exposed to BioMax film with an intensifying screen.

\section{Immunohistochemistry}

Uterine samples were from mixed breed beef cattle and generated for a previously published study (Kimmins \& MacLaren 2001). All heifers were maintained at the Nova Scotia Agricultural College Research Farm (Truro, Nova Scotia, Canada). All procedures performed were in accordance with the guidelines of the Canadian Council on Animal Care 1993. Oestrus was synchronized using a standard double $\mathrm{PGF}_{2 \alpha}$ regimen. In the pregnant group, heifers were inseminated with proven semen at oestrus. In the control group, heifers were not inseminated. On days 16 and 19 of the oestrous cycle, or days 16, 21 and 24 of pregnancy, heifers were slaughtered at a local abattoir, and uteri were collected. Pregnancy was confirmed by the presence of a conceptus. One-cubic centimetre cross-sectioned blocks were dissected in the middle portion of the uterine horn ipsilateral to the corpus luteum in both cyclic and pregnant uteri. The uterine horns were cut into small pieces, frozen in liquid nitrogen and kept at $-80^{\circ} \mathrm{C}$. Before use, the tissues were placed at $-20^{\circ} \mathrm{C}$ overnight. Tissue slices $(7 \mu \mathrm{m})$ were prepared with a cryostat and dried on the slide for $1 \mathrm{~h}$ before fixing with $4 \%$ paraformaldehyde at room temperature for $30 \mathrm{~min}$. The slides were rinsed with $\mathrm{PBS} 3 \times$ for $3 \mathrm{~min}$ followed by two rinses with in PBS $1 \times$ for $5 \mathrm{~min}$. The tissues were then incubated in $3 \% \mathrm{H}_{2} \mathrm{O}_{2}$ diluted in PBS $1 \times$ for $30 \mathrm{~min}$ and washed 3 times in PBS $1 \times$ for $4 \mathrm{~min}$. The tissues were incubated for $1 \mathrm{~h}$ in $10 \%$ goat serum in PBS $1 \times$ and overnight with a 1:4000 dilution of rabbit anti-PGDH antibody in PBS $1 \times$ or with a 1:4000 dilution of pre-immune rabbit serum in PBS $1 \times$ as a negative control. From this point, slides were washed 3 times for $5 \mathrm{~min}$ in PBS $1 \times$ between each incubation. The tissues were incubated with secondary antibody (goat anti-rabbit) 1:200 in PBS $1 \times$ for $30 \mathrm{~min}$, incubated with Vectastain Elite $A B C$ reagent for $30 \mathrm{~min}$, and incubated with $\mathrm{AEC}$ substrate $(0.066 \%$ AEC in acetate buffer, $\mathrm{pH} 5.2$, containing $0.001 \% \mathrm{H}_{2} \mathrm{O}_{2}$ ) until the tissues were stained. The reaction was stopped by dipping the slides twice in water. The counterstaining was carried out with Harris haematoxylin for 2 min and washed in tap water.

\section{Statistical analysis}

Data are presented as the mean \pm S.E.M. Statistical analysis was performed using ANOVA followed by Fisher's Protected Least Significant Difference multiple comparison test (Super ANOVA; Abacus Concepts, Berkeley, CA, USA).

\section{Results}

\section{Sequencing of the Bos taurus lung PGDH cDNA}

We first analysed the sequence of the bovine PGDH cDNA. The complete nucleotide sequence of $\mathrm{PGDH}$ (GenBank Accession number: DQ-231564) was obtained as described in Materials and Methods. The deduced 
amino acid sequence for the bovine $\mathrm{PGDH}$ is $99 \%$, 93\%, $87 \%$ and $87 \%$ identical to that of water buffalo (Mak \& Lee 1998), human (Ensor et al. 1990), mouse (Matsuo et al. 1996) and rat (Zhang et al. 1997) respectively. Comparing these amino acid sequences with those of short-chain dehydrogenases reveals an overall homology of around 20\% (Krook et al. 1990). Similar to all other short-chain dehydrogenases, bovine PGDH possesses the six amino acid residues that are highly conserved in this family and correspond to three glycines at positions 12 , 18 and 131, Asp64, Tyr151 and Lys155 (Tai et al. 2002).

\section{Bovine recombinant PGDH activity}

Bovine recombinant PGDH was overexpressed in E. coli and purified on a nickel-nitrilotriacetic acid column (Ni-NTA His-bind resin). PGDH was able to oxidize NAD ${ }^{+}$, indicating that it was functional. The activity of rbPGDH was determined as described in Materials and Methods. Bovine recombinant $\mathrm{PGDH}$ is able to oxidize $\mathrm{PGE}_{2}$ at a rate of $3.30 \pm 0.13 \mu \mathrm{mole} / \mathrm{min}$ per mg enzyme (Table 1 ), and oxidized $\mathrm{PGF}_{2 \alpha}$ at a comparable (non statistically different) rate of $4.47 \pm 0.11 \mu \mathrm{mole} / \mathrm{min}$ per mg enzyme, at $\mathrm{pH}$ 9.0. We have also tested the formation of $15-$ keto- $^{-P G E_{2}}$ and $15-$-keto-PGF $2 \alpha$ and we have found that $50 \%$ and $100 \%$ of the substrate was converted by rbPGDH at 15 and $60 \mathrm{~min}$ respectively (results shown for $\mathrm{PGE}_{2}$, Fig. 1).

\section{Northern blot analysis of the expression of PGDH mRNA}

Total RNA was extracted from endometrial cells from bovine uteri at different days of the cycle. In all three series of samples that we have tested, mRNA expression varied from one sample to another but we have found a high level of mRNA expression that does not change during the cycle. We have consistently observed a higher level of expression in the endometrium than in the lung (Fig. 2).

\section{Expression of PGDH protein in bovine endometrium throughout the oestrous cycle}

Figure 3 represents the level of expression of PGDH in endometrial cells scraped from whole endometrium at different days of the oestrous cycle. This preparation thus represents the level of expression in total endometrium. Recombinant bPGDH was used in the first lane as a positive control. The antibody generated is able to recognize

Table 1 Enzymatic activity ( $\mu \mathrm{mole} / \mathrm{min} / \mathrm{mg}$ ) of recombinant bovine 15-PGDH.

\begin{tabular}{lcc}
\hline \multirow{2}{*}{ Co-factor } & \multicolumn{2}{c}{ Substrate } \\
\cline { 2 - 3 } $\mathrm{NAD}^{+} \rightarrow \mathrm{NADH}$ & $\mathrm{PGE}_{2}$ & $\mathrm{PGF}_{2 \alpha}$ \\
\hline
\end{tabular}

${ }^{+}$Results are the mean \pm S.E. of 3 separate experiments.

www.reproduction-online.org the recombinant and native protein at the same dilution. There is a modulation of 15-PGDH during the cycle as the enzyme is very low at the beginning of the cycle, increasing progressively until days $16-18$ when it reaches its maximum $(P<0.05)$ before decreasing slightly at the end of the cycle. Our in-house rabbit anti-PGDH antibody can detect as little as $0.5 \mathrm{ng}$ rbPGDH. The rbPGDH is slightly heavier $(\sim 31 \mathrm{kDa})$ than $\mathrm{PGDH}$ extracted from cells $(\sim 29 \mathrm{kDa})$ due to the presence of the $\mathrm{N}$-terminal his-tag.

\section{Immunohistochemical localization of PGDH in the bovine endometrium}

The presence of 15-PGDH protein can be detected by the anti-PGDH antibody in almost all cell types of the endometrium (Fig. 4). In cyclic endometrium, 15-PGDH is expressed in luminal epithelial and stromal cells at low levels whereas the expression is much higher in glandular epithelial cells. 15-PGDH is not detected in blood vessels, suggesting that it is totally absent or expressed at a very low level. We have observed a consistent pattern of expression of 15-PGDH protein during the cycle among the different samples tested. On day 3, there is no or very little 15-PGDH in the tissue. On days 10 (not shown), 16 and 19 there is a high intensity of $15-\mathrm{PGDH}$ in glandular epithelial cells where we observe a gradient of expression in which there are low levels in glands within the luminal epithelium and higher expression within the deep stroma. In pregnant tissues, the pattern of expression is similar except for transient expression in the luminal epithelium on day 21 of pregnancy. There is also expression of $15-\mathrm{PGDH}$ in trophoblast cells on day 21. Both luminal epithelial and trophoblast cell expression are reduced by day 24 of pregnancy.

\section{Discussion}

In the bovine uterus, we show for the first time that 15PGDH is localized principally in glandular epithelial cells and, to a lesser extent, in stromal and epithelial cells (Fig. 4). Moreover, we also demonstrate that the expression of 15-PGDH varies during the oestrous cycle and is sustained during early pregnancy. Prostaglandin catabolism must be considered in addition to biosynthesis in the regulation of their physiological actions. The presence of 15-PGDH near the site of PG production is interesting, because it allows for tight regulation of PG activity in the tissues where they are produced. Our results are concordant with those in human where 15-PGDH is found principally in glandular epithelial and stromal cells (Hapangama et al. 2002). The same group also reported that cyclooxygenase 2 (COX-2), the rate-limiting enzyme in the production of PGs, is localized in the glands, supporting the evidence that glands are the main site for PG synthesis in the human (Lumsden et al. 1984). In the bovine endometrium, however, COX-2 enzyme is expressed mainly in luminal epithelial cells and, to a 


\section{Day of the cycle}
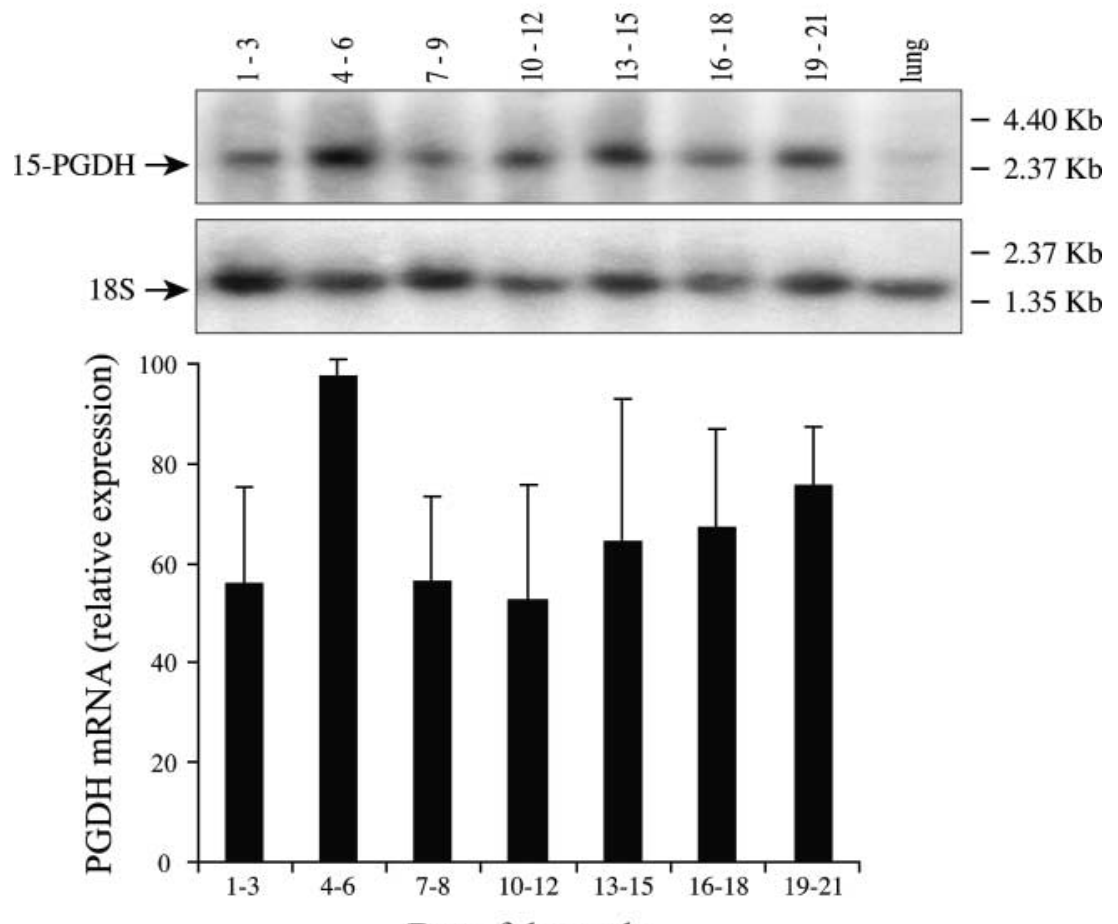

Day of the cycle
Figure 2 Northern blot analysis of the expression of 15-PGDH mRNA in bovine endometrium during the oestrous cycle. Twenty-one uteri representing 3 samples for each of the 7 groups covering the oestrous cycle were collected at the slaughterhouse. The endometrium was removed by scraping and mixed endometrial cells were recovered by centrifugation to prepare RNA samples. Twenty micrograms RNA were loaded on an agarose-formamide gel, transferred onto a nylon membrane and hybridized with total 15-PGDH cDNA probe. 18S ribosomal RNA is shown as the loading control. Lung tissue was used as the positive control. 15-PGDH mRNA is expressed at high levels that did not statistically change over the days of the oestrous cycle. One representative blot from a total of three blots is shown.

\section{Day of the cycle}

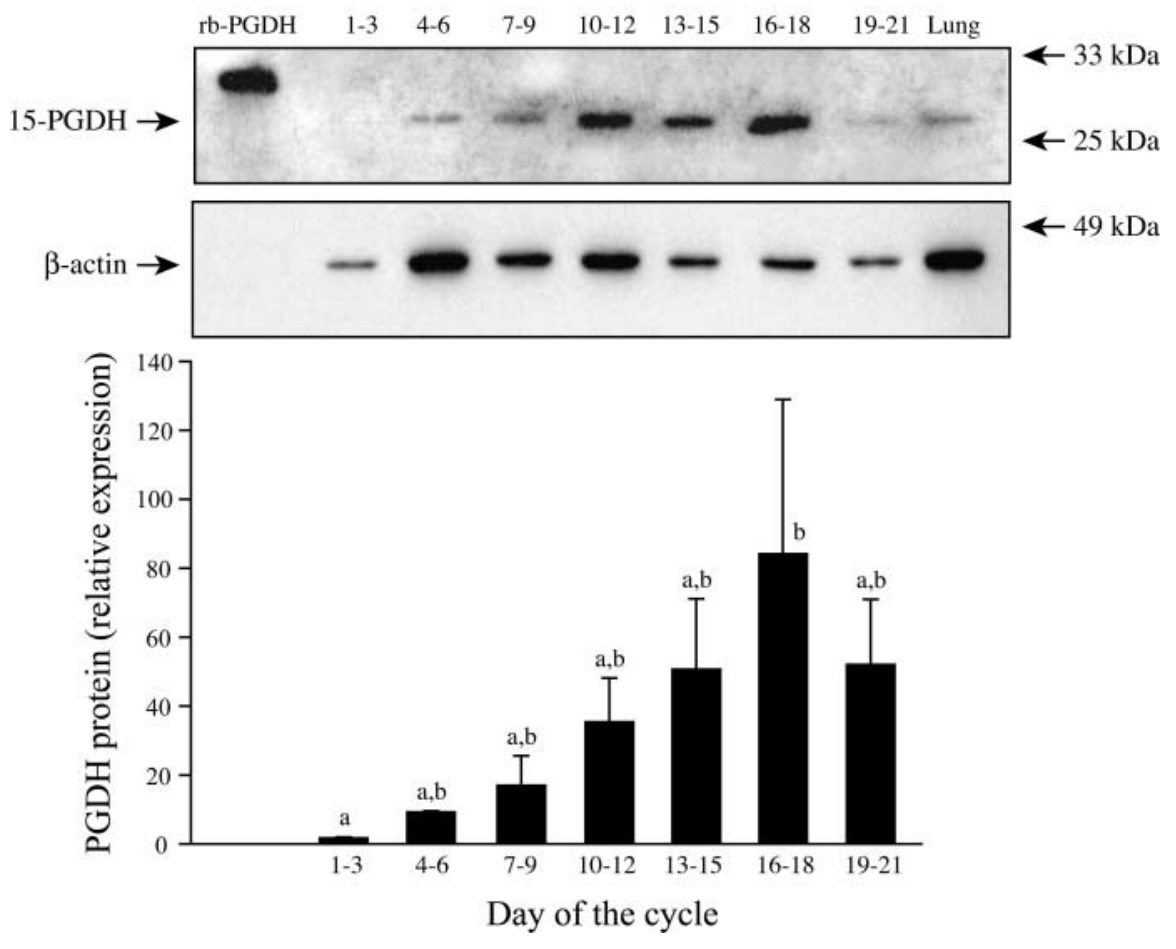

Figure 3 Expression of 15-PGDH protein in bovine endometrium throughout the oestrous cycle. Endometrial cells from the same tissues used for Fig. 2 were used to prepare protein extracts. Aliquots of $15 \mu \mathrm{g}$ total proteins were loaded on a polyacrylamide gel and transferred onto a nitrocellulose membrane. (Top panel) The anti-PGDH antibody generated recognises both the recombinant and native 15 -PGDH (0.5 ng). $\beta$-actin was used as an internal control for quantity of protein, and lung tissue was used as a positive control. One representative blot out of three is shown. (Bottom panel) The graph represents the mean \pm S.E.M. of three different sets of the seven sample groups covering the oestrous cycle (relative densitometric values of $15-\mathrm{PGDH} / \beta$-actin). Values with different superscripts are significantly different $(P<0.05)$ 
D3C
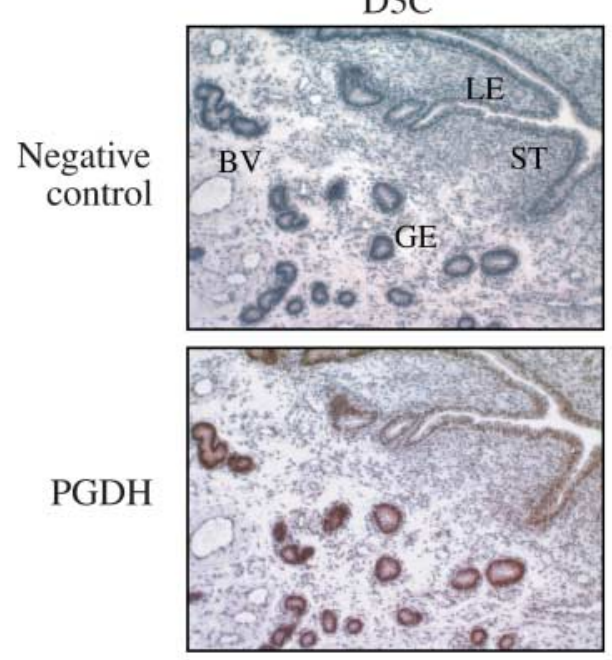

D16P
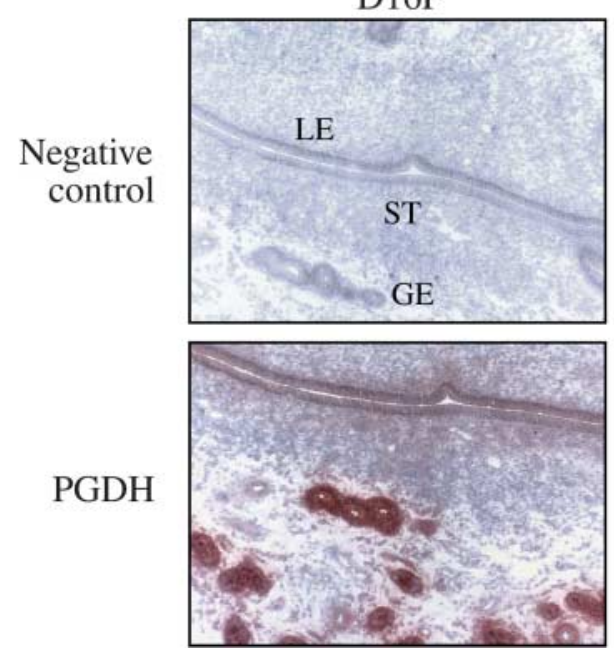

D16C
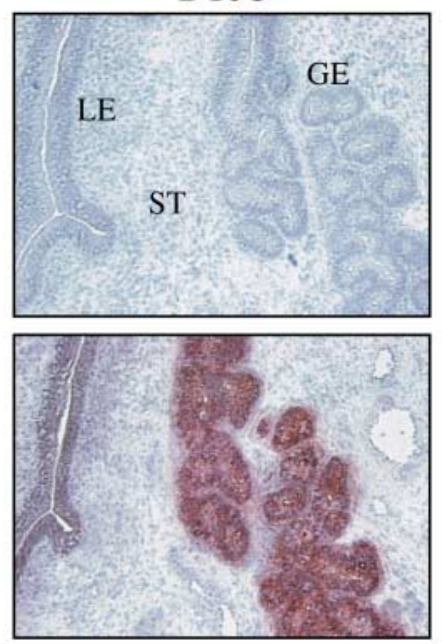

D21P
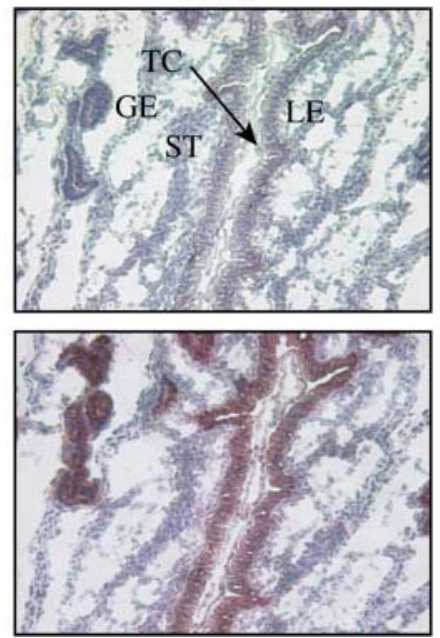

D19C


Figure 4 Immunohistochemistry of 15-PGDH in bovine endometrium. Tissue slices $(7 \mu \mathrm{m})$ were prepared from blocks of fixed endometrium at the indicated days of the oestrous cycle (D3C, D16C, D19C) or early pregnancy (D16P, D21P, D24P) and were mounted on microscope slides. The slides were incubated for $1 \mathrm{~h}$ in 10\% goat serum in PBS $1 \times$ and overnight with a 1:4000 dilution of rabbit anti-PGDH antibody in PBS $1 \times$ or with a 1:4000 dilution of pre-immune rabbit serum in PBS $1 \times$ as a negative control. The presence of 15-PGDH appears as a reddish colour. It is very low or absent on day 3, and higher on day 16 and on day 19 of the oestrous cycle. 15-PGDH is present at low levels in luminal epithelial (LE) and stromal (ST) cells and at very high levels in glandular epithelial cells (GE). 15-PGDH is not detectable in blood vessels (BV). During early pregnancy, staining is equivalent or higher in glands and is maintained at least until day 24 . There is transient high staining in luminal epithelial and trophoblast cells (TC) on day 21. All frames taken at $100 \times$. Selected frames from a total of 12 cyclic and 7 pregnant animals are shown.

lesser extent, in glandular epithelial cells (Emond et al. 2004). The bovine endometrium is known to exhibit celltype-specific $\mathrm{PGE}_{2}$ and $\mathrm{PGF}_{2 \alpha}$ production, occurring primarily in stromal and luminal epithelial cells respectively. Moreover, our laboratory has identified the PGF synthase (PGFS) responsible for the production of $\mathrm{PGF}_{2 \alpha}$ in bovine endometrium as AKR1B5, which is localized in the glandular and luminal epithelium (Madore et al. 2003). Therefore, bovine endometrial PGFS (AKR1B5) and 15-PGDH are co-localized in the endometrial glands.

During the oestrous cycle, immuno-localization of 15-PGDH in bovine endometrial cells (Fig. 4) follows a pattern of expression similar to that found in whole endometrium by Western blot analysis (Fig. 3). The 15PGDH enzyme is modulated and reaches its maximal expression on days 16-18. We have found previously that COX-2 (Arosh et al. 2002), the bovine endometrial PGFS (Madore et al. 2003) and the bovine PG transporter (bPGT) (Banu et al. 2003) proteins show a similar pattern of expression during the cycle, with maximal expression also on days 16-18, but bPGT is not expressed in glandular epithelial cells. At this period, the luteolytic mechanism will engage if the presence of a viable embryo is not detected. In such a case, uterine 
$\mathrm{PGF}_{2 \alpha}$ levels begin to increase, oestrogen rises and progesterone falls. Endometrial $\mathrm{PGF}_{2 \alpha}$ and luteal oxytocin generate an amplification loop culminating in functional and structural luteolysis (McCracken et al. 1999). The high levels of COX-2 and PGFS that we have reported are necessary to sustain $\mathrm{PGF}_{2 \alpha}$ production (Arosh et al. 2002, Madore et al. 2003). Therefore, the presence of 15-PGDH may serve as a regulatory feedback to restrict $\mathrm{PGF}_{2 \alpha}$ in case of a late detection of the embryonic signal or to prevent the action of the PGs produced in gland cells. The transient expression of 15-PGDH at the feto-maternal interface on day 21 of pregnancy supports such a role for the early establishment of pregnancy. Moreover, co-expression of biosynthetic, transport and catabolic enzymes in a single cell has been reported recently to be an important regulatory mechanism of PG action (Nomura et al. 2005).

The levels of 15-PGDH are not only regulated temporally in the glands during the cycle, but also spatially, with increased expression in the deep stroma adjacent to the myometrium. We can hypothesize that interactions between stromal and epithelial cells regulate the level of expression of 15-PGDH protein. It was shown that stromal-epithelial interactions are critical for the differentiation of the epithelium (Donjacour \& Cunha 1991). In the mouse, stromal cells are necessary for expression of sex steroid action on epithelial cells (Donjacour \& Cunha 1991, Bigsby 2002). Therefore, cellular interactions may regulate the expression of 15$\mathrm{PGDH}$. Indeed, stromal influence is greater in epithelial cells of deep glands than in luminal epithelial cells. Moreover, we have not been able to detect 15-PGDH messenger or protein in isolated bovine endometrial epithelial cells in primary culture (results not shown), a finding that may explain the high levels of PGs produced in these cultures and the absence of $15 \mathrm{~K}$ metabolites in their culture medium (Madore et al. 2003). However, our results with pregnant tissues demonstrate that high levels of 15-PGDH expression occur in luminal epithelial cells adjacent to embryonic tissues. This expression is transient and potentially induced by embryonic factors. It is, however, unlikely to result from trophoblast interferon (IFN $\tau$ ) as we have shown recently that it does not influence 15-PGDH expression in the bovine endometrium (Arosh et al. 2004b).

A number of correlations between 15-PGDH enzyme activity and progesterone levels in human placental and uterine tissues suggest that 15-PGDH is under steroidal control. It was demonstrated that human and mouse 15$\mathrm{PGDH}$ promoters contain progesterone, oestrogen and glucocorticoid receptor binding sites (Matsuo et al. 1997, Greenland et al. 2000). In a more recent study, Patel \& Challis (2002) demonstrated that glucocorticoids and progestins regulate $15-\mathrm{PGDH}$ in human chorion and placental trophoblast cells in vitro. However, we report here that bovine 15-PGDH mRNA, in contrast to protein, does not appear to respond to progesterone and/or oestradiol because its expression does not vary during the oestrous cycle (Fig. 2). It is possible that the appearance of 15-PGDH protein is regulated at the posttranscriptional or post-translational level.

The lungs are the primary site of prostaglandins degradation and in some mammals such as sheep more than $99 \%$ of $\mathrm{PGF}_{2 \alpha}$ is metabolized during a single passage in the pulmonary circulation (McCracken et al. 1999). For this reason, we used the bovine lung as the source to clone 15-PGDH. Therefore, we were quite surprised to observe that the level of expression of 15-PGDH mRNA is much lower in the lung than in the endometrium. One hypothesis for this relatively low level of 15-PGDH in the bovine lung is that the piece of lung we used did not contain large bronchioles, where the highest 15PGDH activity has been reported (Gargiulo et al. 1988). Compared with human and sheep, bovine 15-PGDH activity has previously been reported to be lower in lung (McCracken et al. 1999), and in endometrium, placenta and fetal membranes during late gestation and parturition (Keirse \& Turnbull 1975, Keirse et al. 1978, Skinner \& Challis 1985, Janszen et al. 1994). In vivo, the net 15-PGDH activity can also be influenced by limitation in the transport of PGs inside cells. Indeed, it was shown recently that PGs are charged negatively and do not cross cell membranes freely, as assumed initially, but rather require a specialized transporter. In this respect, we have identified the bovine PG transporter (Banu et al. 2003) and found that its expression was also regulated in a spatio-temporal manner with maximal expression between days 13 to 18 , exactly as found here for 15-PGDH. The activity found for the bovine recombinant $15-\mathrm{PGDH}$ (Table 1) is similar for $\mathrm{PGF}_{2 \alpha}$ and $\mathrm{PGE}_{2}$ and thus is unlikely to contribute to selective inactivation of one PG or the other to favour a return to oestrus or recognition of pregnancy. Another hypothesis may be that, in the cow, local metabolism of PGs is more important in the endometrium than in the lung. This would explain why in early studies on the recognition of pregnancy, PGFM was found at high levels no matter from where the blood was collected. Endometrial expression of 15-PGDH allows for a possible tight regulation of the mechanisms taking place in the reproductive tract to effect luteolysis, recognition of pregnancy, implantation or parturition. Indeed, disturbance in the $\mathrm{PGE}_{2} / \mathrm{PGF}_{2 \alpha}$ ratio at any of these steps can result in reproductive failure.

In summary, we show that 15-PGDH is present in the bovine endometrium, is modulated throughout the oestrous cycle and is expressed at the feto-maternal interface. Its localization principally in the glandular epithelium and its maximal co-expression with PGFS on days 16-18 suggest that there is a strong link between the formation of $\mathrm{PGF}_{2 \alpha}$ and its destruction in the endometrium. 


\section{Acknowledgements}

The authors declare that there is no conflict of interest that would prejudice the impartiality of this scientific work.

\section{References}

Arosh JA, Parent J, Chapdelaine P, Sirois J \& Fortier MA 2002 Expression of cyclooxygenase 1 and 2 and prostaglandin $\mathrm{E}$ synthase in bovine endometrial tissue during the oestrous cycle. Biology of Reproduction 67 161-169.

Arosh JA, Banu SK, Chapdelaine P, Madore E, Sirois J \& Fortier MA 2004a Prostaglandin biosynthesis, transport, and signaling in corpus luteum: a basis for autoregulation of luteal function. Endocrinology $1452551-2560$.

Arosh JA, Banu SK, Kimmins S, Chapdelaine P, MacLaren LA \& Fortier MA 2004b Effect of interferon- $\tau$ on prostaglandin biosynthesis, transport, and signaling at the time of maternal recognition of pregnancy in cattle: evidence of polycrine actions of prostaglandin $\mathrm{E}_{2}$. Endocrinology 145 5280-2593.

Banu SK, Arosh JA, Chapdelaine P \& Fortier MA 2003 Molecular cloning and spatio-temporal expression of the prostaglandin transporter: a basis for the action of prostaglandins in the bovine reproductive system. PNAS 100 11747-11752.

Bigsby RM 2002 Control of growth and differentiation of the endometrium: the role of the tissue interactions. Annals of the New York Academy of Sciences 955 110-117.

Braithwaite SS \& Jarabak J 1974 Studies on a 15-hydroxyprostaglandin dehydrogenase from human placenta. Journal of Biological Chemistry 250 2315-2318.

Chapdelaine P, Vignola K \& Fortier MA 2001 Protein estimation directly from SDS-PAGE loading buffer for standardization of samples from cell lysates or tissue homogenates before Western blot analysis. Biotechniques 31 478-482.

Donjacour AA \& Cunha GR 1991 Stromal regulation of epithelial function. Cancer Treatment and Research 53 335-364.

Emond V, Arosh JA, Kimmins S, Fortier MA, MacLaren LA \& Lambert RD 2004 The expression of cyclooxygenase-2 and granulocytemacrophage colony-stimulating factor in the endometrial epithelium of the cow is up-regulated in response to intra-uterine injections of interferon-tau. Biology of Reproduction 70 54-64.

Ensor CM \& Tai HH 1992 Expression of the cDNA for NAD ${ }^{+}$-dependent 15-hydroxyprostaglandin dehydrogenase as a catalytically active enzyme in Escherichia coli. Prostaglandins, Leukotrienes and Essential Fatty Acids 46 219-222.

Ensor CM \& Tai HH 1995 15-Hydroxyprostaglandin dehydrogenase. Journal of Lipid Mediators and Cell Signaling 12 313-319.

Ensor CM, Yang JY, Okita RT \& Tai HH 1990 Cloning and sequence analysis of the cDNA for human placental $\mathrm{NAD}^{+}$-dependent 15-hydroxyprostaglandin dehydrogenase. Journal of Biological Chemistry $26514888-14891$.

Gargiulo AM, Pedini V, Ceccarelli P \& Monaci M 1988 Histochemical localization of prostaglandin activity for $\mathrm{PGF}_{2 \alpha}$ in some bovine tissues. Prostaglandins, Leukotrienes and Essential Fatty Acids 32 71-74.

Greenland KJ, Jantke I, Jenatschke S, Bracken KE, Vinson C \& Gellersen B 2000 The human $\mathrm{NAD}^{+}$-dependent 15-hydroxyprostaglandin dehydrogenase gene promoter is controlled by Ets and activating protein-1 transcription factors and progesterone. Endocrinology $141581-597$.

Hapangama DK, Critchley HOD, Henderson TA \& Baird DT 2002 Mifepristone-induced vaginal bleeding is associated with increased immunostaining for cyclooxygenase-2 and decrease in prostaglandin dehydrogenase in luteal phase endometrium. Journal of Clinical Endocrinology and Metabolism 87 5229-5234.

Janszen BPM, Bevers MM, Erwich JJH, Van Der Weijden GC, Keirse MJNC \& Taverne MAM 1994 15-Hydroxyprostaglandin dehy- drogenase activity in uterine tissues of late gestational and parturient cows. Placenta 15 89-94.

Jarabak J \& Fried J 1979 Comparison of substrate specificities of the human $\mathrm{NAD}^{+}$- and $\mathrm{NADP}^{+}$-linked 15 -hydroxyprostaglandin dehydrogenases. Prostaglandins 18 241-246.

Kang J, Chapdelaine P, Parent J, Madore E, Laberge PY \& Fortier MA 2005 Expression of human prostaglandin transporter in the human endometrium across the menstrual cycle. Journal of Clinical Endocrinology and Metabolism $2005902308-2313$.

Kankofer M 1999 The enzymes responsible for the metabolism of prostaglandins in bovine placenta. Prostaglandins, Leukotrienes and Essential Fatty Acids 61 359-362.

Keirse MJNC \& Turnbull AC 1975 Metabolism of prostaglandins within the pregnant uterus. British Journal of Obstetrics and Gynaecology 82 887-893.

Keirse MJNC, Hicks BR, Kendall JZ \& Mitchell MD 1978 Comparison of intrauterine prostaglandin metabolism during pregnancy in man, sheep and guinea-pig. European Journal of Obstetrics and Gynaecology Reprod Biol 8 195-203.

Kimmins S \& MacLaren LA 2001 Oestrous cycle and pregnancy effects on the distribution of oestrogen and progesterone receptors in bovine endometrium. Placenta 8-9 742-748.

Krook M, Marekov L \& Jornall H 1990 Purification and structural characterization of placental $\mathrm{NAD}^{+}$-linked 15-hydroxyprostaglandin dehydrogenase. The primary structure reveals the enzyme to belong to the short-chain alcohol dehydrogenase family. Biochemistry $\mathbf{2 9}$ $738-743$.

Lin YM \& Jarabak J 1978 Isolation of two proteins with 9-ketoprostaglandin reductase and NADP-linked 15-hydroxyprostaglandin dehydrogenase activities and studies on their inhibition. Biochemical and Biophysical Research Communications 81 1227-1234.

Lumsden MA, Brown A \& Baird DT 1984 Prostaglandin production from homogenate of separated glandular epithelium and stroma from human endometrium. Prostaglandins 28 485-496.

McCracken JA, Custer EE \& Lamsa JC 1999 Luteolysis: a neuroendocrine-mediated event. Physiological Reviews 79 263-324.

Madore E, Harvey N, Parent J, Chapdelaine P, Arosh JA \& Fortier MA 2003 An aldose reductase with $20 \alpha$-hydroxysteroid dehydrogenase activity is most likely the enzyme responsible for the production of prostaglandin $\mathrm{F}_{2 \alpha}$ in the bovine endometrium. Journal of Biological Chemistry 278 11205-11212.

Mak OT \& Lee YS (1998). Cloning and sequence analysis of the CDNA for the bovine lung $\mathrm{NAD}^{+}$-dependent 15-hydroxyprostaglandin dehydrogenase. Unpublished. GenBank Accession number: AJ222837.

Matsuo M, Ensor CM \& Tai HH 1996 Cloning and expression of the cDNA for mouse $\mathrm{NAD}^{+}$-dependent 15-hydroxyprostaglandin dehydrogenase. Biochimica et Biophysica Acta 1309 21-24.

Matsuo M, Ensor CM \& Tai HH 1997 Characterization of the genomic structure and promoter of the mouse $\mathrm{NAD}^{+}$-dependent 15-hydroxyprostaglandin dehydrogenase gene. Biochemical and Biophysical Research Communications 235 582-586.

Nomura T, Chang HY, Lu R, Hankin J, Murphy RC \& Shuster VL 2005 Prostaglandin signalling in the renal collecting duct: release, reuptake and oxidation in the same cell. Journal of Biological Chemistry 280 28424-28429.

Okita RT \& Okita JR 1996 Prostaglandin-metabolizing enzymes during pregnancy: characterization of $\mathrm{NAD}^{+}$-dependent prostaglandin dehydrogenase, carbonyl reductase, and cytochrome P450-dependent prostaglandin omega-hydroxylase. Critical Reviews in Biochemistry and Molecular Biology 31 101-126.

Pace-Asciak CR 1980 Developmental aspects of the prostaglandin biosynthetic and catabolic systems. Seminars in Perinatology $\mathbf{4}$ $15-21$.

Patel FA \& Challis JRG 2001 Prostaglandins and uterine activity. Frontiers in Hormone Research 27 31-56.

Patel FA \& Challis JRG 2002 Cortisol/progesterone antagonism in regulation of 15-hydroxyprostaglandin dehydrogenase activity and mRNA levels in human chorion and placental trophoblast cells at 
term. Journal of Clinical Endocrinology and Metabolism 87 700-708.

Piper PJ, Vane JR \& Wyllie JH 1970 Inactivation of prostaglandins by the lungs. Nature 225 600-604.

Skinner KA \& Challis JRG 1985 Changes in the synthesis and metabolism of prostaglandins by human fetal membranes and deciduas at labor. American Journal of Obstetrics and Gynecology 151 519-523.

Tai HH, Ensor CM, Tong M, Zhou H \& Yan F 2002 Prostaglandin catabolizing enzymes. Prostaglandins and other Lipid Mediators 68-69 483-493.

Yamazaki M \& Sasaki M 1975 Formation of prostaglandin $E_{1}$ from 15ketoprostaglandin $\mathrm{E}_{1}$ by guinea pig lung 15-hydroxyprostaglandin dehydrogenase. Biochemical and Biophysical Research Communications $\mathbf{6 6} 255-261$.

Zhang H, Matsuo M, Zhou H, Ensor CM \& Tai HH 1997 Cloning and expression of the cDNA for rat $\mathrm{NAD}^{+}$-dependent 15-hydroxyprostaglandin dehydrogenase. Gene 188 41-44.

Received 15 May 2005

First decision 13 June 2005

Revised manuscript received 14 October 2005

Accepted 22 November 2005 